- improved offerings may not appease NIDA's critics - including US states such as Colorado, which legalized recreational pot use in 2012. In December, the Colorado state government asked the federal government to allow state universities to grow marijuana for research, citing bureaucratic hurdles in obtaining products from NIDA and from private growers overseas.

And the agency's most potent strains still fall short of the most powerful street pot. At least $90 \%$ of the marijuana seized by the US Drug Enforcement Administration (DEA) contains high levels of THC - often more than 20\% by weight. NIDA's pot contains $12 \%$ THC at most. "Let me just say: lame," says Rick Doblin, director of the Multidisciplinary Association for Psychedelic Studies, a non-profit organization in Santa Cruz, California, that funds research into mind-altering drugs.

It is not clear how NIDA's plants compare with those distributed by medical-marijuana dispensaries. Although legal under local state laws, such dispensaries are still illegal under federal law, so researchers cannot simply buy pot there to test. And because Congress voted last year to prohibit the federal government from raiding such facilities, the products are not available for NIDA to study, either. "I don't know what dispensaries have," says ElSohly. "I wish I did."

The pool of US scientists who study marijuana is small, and to Volkow's surprise, it has

not grown despite the increasing availability of legal pot and NIDA's efforts to ease limits on such research. Volkow suspects that scientists may simply need time to plan new experiments that involve marijuana, which must be evaluated by NIDA, the DEA and, in the case of clinical research, the Food and Drug Administration.

Donald Abrams, a physician at the University of California, San Francisco, who studies cannabinoids as cancer therapies, offers another theory. The rise of precision medical technologies such as gene therapy makes

"We want to be able to evaluate the claims that marijuana is therapeutically beneficial." it less attractive to study a plant, he says - particularly one as controversial as marijuana.

Doblin suggests that successful therapies derived from marijuana are most likely to emerge outside the United States, in countries where licensed growers can provide the plant at relatively low cost and in high quantities. GW Pharmaceuticals in Salisbury, UK, uses marijuana from its private farm to produce Sativex (nabiximols), a multiple-sclerosis drug that is approved for use in 27 countries. And private growers in Israel and Canada produce research- and clinicalgrade pot that is cheaper than NIDA's crop. (The agency charges researchers US $\$ 1,525$ per kilogram, or $\$ 7$ per cigarette.)
NIDA says that it plans to limit its pot programme to individual researchers for the time being. But there is a nascent push in Congress to end the agency's monopoly on research marijuana: bipartisan legislation introduced in the Senate on 10 March would allow at least three growers to obtain licences to cultivate pot for studies.

If the US government decides to expand legal marijuana production significantly, Canada could serve as a model. In April 2014, the Canadian government began allowing private firms to apply to grow medical marijuana; it has since awarded 16 licences. Canadian researchers who want to study marijuana or perform clinical trials obtain the drug by partnering with a grower. Because multiple companies hold licences, there is wide diversity in the strains available.

"The system that's implemented right now will allow for really good collaborations," says Joshua Eades, chief science officer of the medical-marijuana producer Tilray in Nanaimo, Canada. The company is working with researchers at the University of British Columbia Okanagan in Kelowna on an 40-person clinical trial of marijuana to treat posttraumatic stress disorder. Expected to start in early summer, it will be one of the largest-ever tests of marijuana for mental health.

With pot increasingly available to science outside the United States, Doblin says, "the NIDA monopoly is doomed." -

\title{
Crunch time for Canada's role in mega-telescope
}

\section{Astronomers ask federal government to honour promise for Thirty Meter Telescope.}

\section{BY ALEXANDRA WITZE}

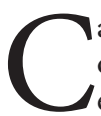
anadian astronomers have been a driving force in the Thirty Meter Telescope (TMT) project since planning began more than a decade ago. But now, as clearing begins on Mauna Kea, Hawaii, where the mighty telescope will sit, they risk being left out in the cold. As early as next month, the Canadian government is expected to release its 2015 budget - and if it does not contain the Can\$300 million (US\$236 million) that astronomers are asking for the TMT, Canada may become a bit player in the project that it has helped to lead for so long.

Those planning the TMT had expected Canada's Can\$300-million commitment to materialize last year. It did not. All the other major players - two California university systems, along with the national observatories of Japan, China and India - have committed substantial future funds to the billion-dollar-plus optical and infrared telescope. The site had its ground-breaking and blessing ceremony last autumn, and telescope parts are already being built around the world - the project is essentially waiting for Canada in order to move into full gear (see 'The long view').

Canada had long promised to supply the gigantic steel enclosure that will surround the 492-segment mirror, as well as other contributions such as the advanced optics system that will cancel out atmospheric blurring to produce clear, sharp views of the cosmos. Pulling out now "would be a shattering loss of obligation on our part", says Donald Brooks, a chemist at the
University of British Columbia in Vancouver and chair of the council of the Association of Canadian Universities for Research in Astronomy, the organization through which Canada participates in the TMT.

The TMT board will hold a crucial meeting on 29 April in Pasadena, California, where it hopes to get Canada's full commitment. "We're looking forward to Canada being a partner," says Ed Stone, a space physicist at the California Institute of Technology in Pasadena and executive director of the TMT International Observatory. To enable that, he adds, "we have flexibility to do additional replanning if necessary".

Canadian astronomers have been arguing the TMT's case to the government in Ottawa. They note that astronomy is one of Canada's highestrated research fields, and that they have ranked 


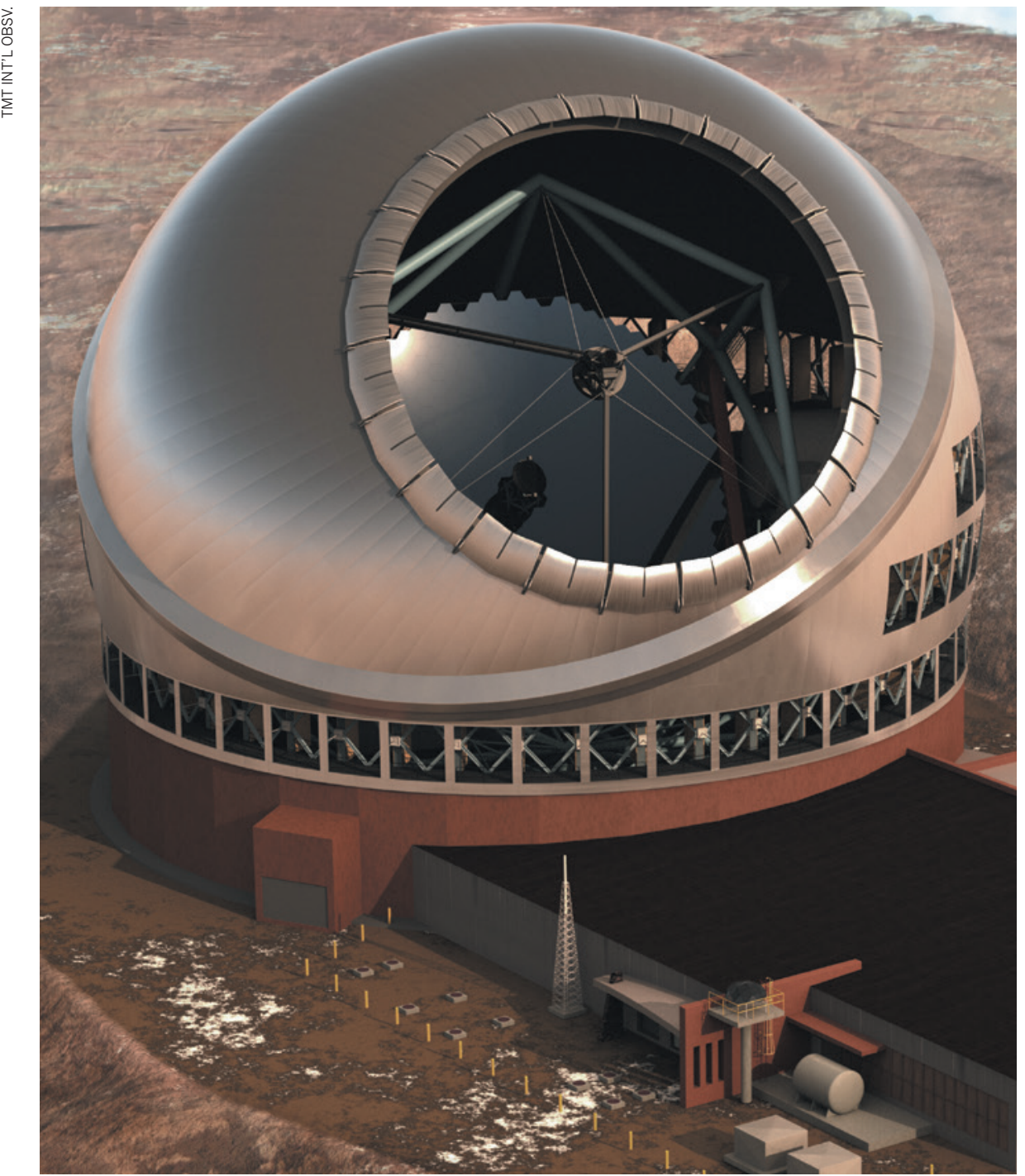

Partners in the Thirty Meter Telescope (seen here in an artist's impression) held a ground-breaking ceremony in Mauna Kea, Hawaii, last year.

the TMT as their most-wanted project for more than a decade. At this point, "it's a question of, is Canada going to be part of it or not?" says Christine Wilson, an astronomer at McMaster University in Hamilton, Ontario, and president of the Canadian Astronomical Society.

This year, unlike last, presidents of the University of Toronto and the University of British Columbia have also been personally making the case to government officials. And an independent industry report noted the commercial value of developing TMT technologies such as optics, amplifiers and antennas.

All that effort adds up to slightly more optimism this year than last. "We know we're on their radar screen, but that doesn't mean we know what the decision is," says Raymond Carlberg, an astronomer at the University of Toronto and the Canadian project director for the TMT.

The TMT will be nearly 100 times more powerful than the best 10-metre telescopes available today. It will tackle major questions including the composition of extrasolar planets' atmospheres, the nature of dark matter and dark energy and the evolution of galaxies in the early Universe, says Paul Hickson, an astronomer at the University of British Columbia. The TMT will compete with two similarclass telescopes also under construction: the Giant Magellan Telescope and the European Extremely Large Telescope, both in Chile.

For now, the biggest telescopes routinely used by Canadian astronomers are the twin 8-metre Gemini facilities in Chile and Hawaii. Moving to the next generation of telescopes will be key to keeping Canadian astronomy competitive, says Carlberg. "We need to participate in first-rate science," he adds.

Canada has already spent more than Can\$35 million on drawing up early engineering plans for the project and other design and development work. Of the new money, Can $\$ 150$ million would go towards the telescope enclosure. It would be built by a company in suburban Vancouver that has made other large telescope domes before (and that spun off its expertise into building amusement-park structures such as Harry

\section{THE LONG VIEW}

The Thirty Meter Telescope's power could reveal new information about the early Universe and conditions outside the Solar System.

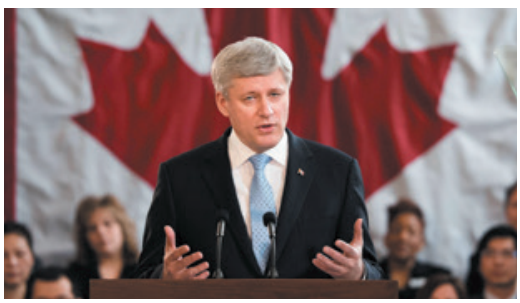

2003 The Association of Canadian Universities for Research in Astronomy, the University of California and the California Institute of Technology form a non-profit corporation that aims to build the Thirty Meter Telescope.

\section{8}

Japan joins the project.

\section{9}

China joins. Mauna Kea, Hawaii, is chosen as the location. The project moves into an early construction phase, helped in part by money from the Gordon and Betty Moore Foundation in Palo Alto, California.

\section{India joins}

2014 All partners, except Canada, formalize their roles. A ground-blessing ceremony kicks off construction.

2015 Canadian astronomers wait for the country's budget to be announced by Prime Minister Stephen Harper (pictured).

Potter-themed rides in Florida and Japan). The remaining Can $\$ 150$ million would pay for scientific instruments and other costs over the nine years it will take to build the TMT.

As the decision on the telescope nears, it is almost impossible to predict what Prime Minister Stephen Harper's government will do, says Paul Dufour, a science-policy consultant in Gatineau, Quebec. The Canadian economy depends heavily on oil revenues, which have been plunging, and the finance minister has delayed release of the budget until April, several months later than normal.

But Dufour notes that big investments in international science projects have come through in recent years. In 2014, the government approved Can $\$ 222$ million for TRIUMF, the national particle-physics laboratory in Vancouver that is closely linked to the international CERN facility near Geneva, Switzerland.

Astronomers are watching and waiting. "It will come down to a political decision at a pretty high level," says Brooks. "We don't know when that day will come." 